\title{
Alternatives to Invasive Plants Commonly Found in North Florida Landscapes ${ }^{1}$
}

\author{
Gary W. Knox, Sandra B. Wilson, Zhanao Deng, and Rosanna Freyre ${ }^{2}$
}

Invasive plants are non-native plants that form expanding populations in natural areas and other plant communities with which they were not previously associated (Langeland 2012). Invasive plants can cause ecological impacts, such as displacing native plants and associated wildlife or altering natural water flow and fire patterns.

Some ornamentals listed as invasive by the University of Florida IFAS Assessment of Non-Native Plants in Florida's Natural Areas or by the Florida Exotic Pest Plant Council are still in commercial production and widely found in Florida landscapes. Homeowners might replace invasive plants if non-invasive alternatives are researched, publicized and made readily available. By shifting production and use from invasive ornamentals to native or non-invasive cultivars, the nursery and landscape industry could benefit from potential revenue while fostering greater collaboration with state agencies and environmental groups.

University of Florida research and Extension efforts over the last 10 years have focused on identifying non-invasive alternatives by assessing the invasive traits of popular non-native ornamentals, related genera, and their cultivars. In more recent years, University of Florida breeding efforts have focused on producing and trialing new non-invasive cultivars. Table 1 lists native and non-invasive, non-native ornamentals as alternatives to invasive plants commonly used in Florida landscapes. Only plants considered to be generally available in the nursery trade are listed. Alternative plants are similar to respective invasive plants as much as possible in terms of size, habit, texture, and flower color. Non-native, non-invasive plants in Table 1 were determined to be non-invasive by the IFAS Assessment of Non-Native Plants in Florida's Natural Areas (IFAS Invasive Plant Working Group 2008) or have not yet been evaluated.

\section{References}

Fox, A. M., D. R. Gordon, J. A. Dusky, L. Tyson, and R. K. Stocker. 2009. IFAS Assessment of Non-Native Plants in Florida's Natural Areas: Status Assessment. Gainesville: University of Florida Institute of Food and Agricultural Sciences. http://plants.ifas.ufl.edu/assessment/pdfs/Final_PDF_SS-AGR-225_04.30.09.pdf.

Fox, A. M., D. R. Gordon, C. Gantz, G. W. Knox, and S. B. Wilson. 2007. IFAS Assessment: Infraspecific Taxon Protocol. Gainesville: University of Florida Institute of Food and Agricultural Sciences. http://plants.ifas.ufl.edu/assessment/ infraspecific_taxon_protocol.html.

IFAS Invasive Plant Working Group. 2008. IFAS Assessment of Non-Native Plants in Florida's Natural Areas. Gainesville: University of Florida Institute of Food and Agricultural Sciences. http://plants.ifas.ufl.edu/assessment/.

Langeland, K. A. 2012. Help Protect Florida's Natural Areas from Non-Native Invasive Plants. Circular 1204. Gainesville: University of Florida Institute of Food and Agricultural Sciences. http://edis.ifas.ufl.edu/ag108.

1. This document is ENH1206, one of a series of the Environmental Horticulture Department, UF/IFAS Extension. Original publication date August 2013. Visit the EDIS website at http://edis.ifas.ufl.edu.

2. Gary W. Knox, Extension specialist and professor, Environmental Horticulture Department, North Florida Research and Education Center, Quincy, FL; Sandra B. Wilson, professor, Environmental Horticulture Department, Indian River Research and Education Center, Fort Pierce, FL; Zhanao Deng, associate professor, Environmental Horticulture Department, Gulf Coast Research and Education Center, Wimauma, FL; and Rosanna Freyre, research scientist, Environmental Horticulture Department, University of Florida Institute of Food and Agricultural Sciences, Gainesville, FL, 32611. 


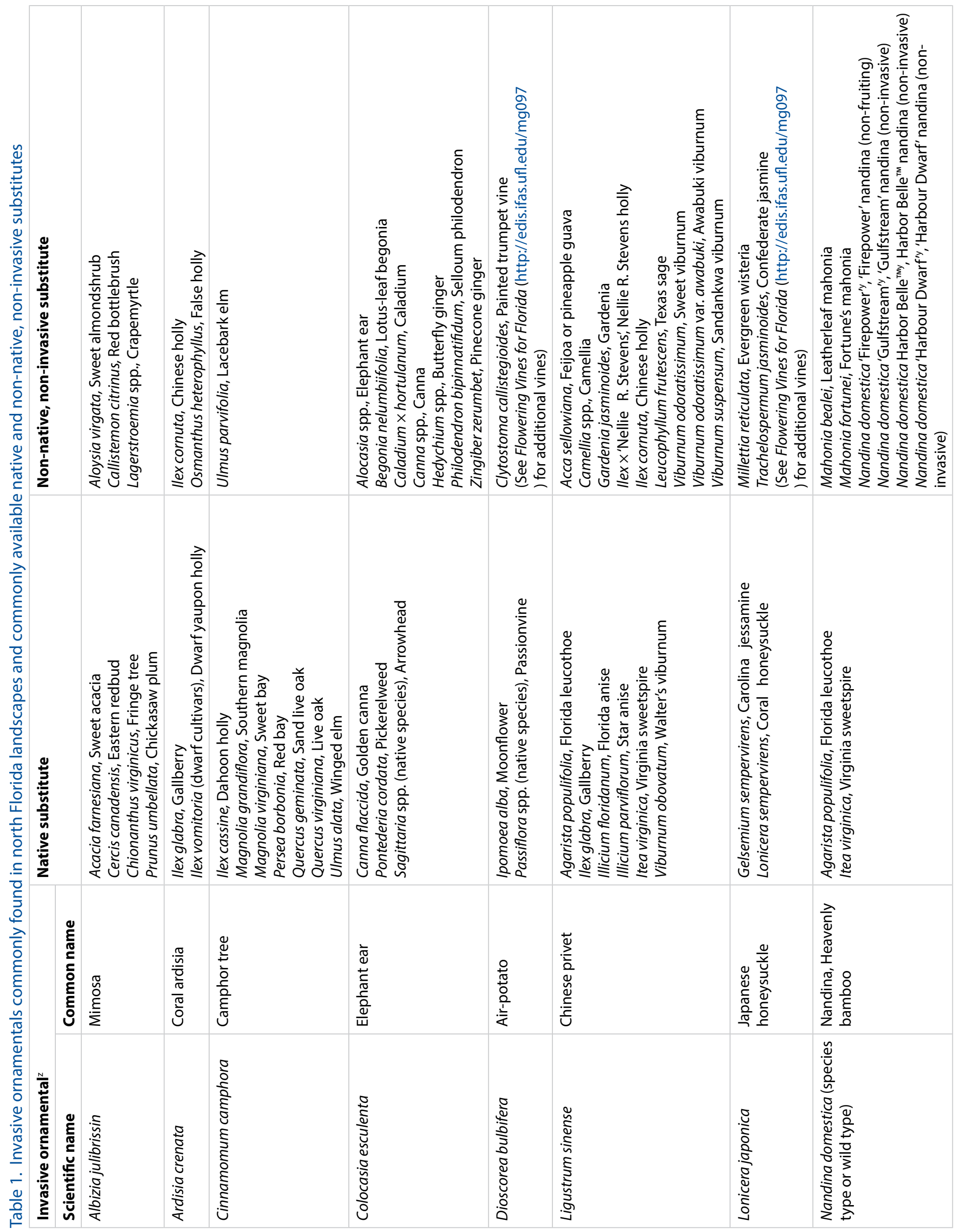




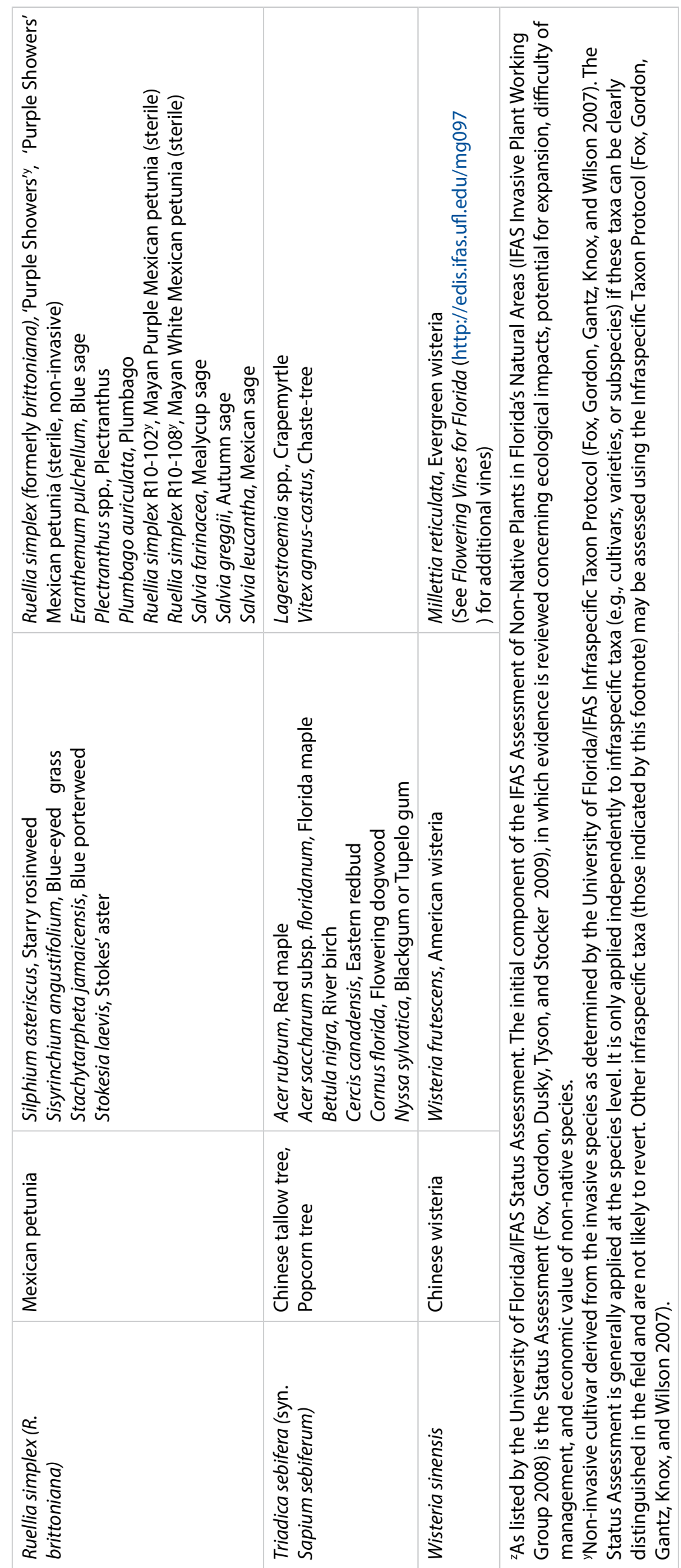

